\title{
PEMBUATAN PROGRAM APLIKASI PEMELIHARAAN MESIN TERJADUAL DI LABORATORIUM MEKANIK POLMAN NEGERI BANGKA BELITUNG
}

\author{
Hasdiansah $^{1}$ \\ ${ }^{1}$ Jurusan Teknik Mesin - Politeknik Manufaktur Negeri Bangka Belitung \\ Kawasan Industri Air Kantung, Sungailiat - Bangka, 33211 \\ Tel: 0717-93586, Fax: 0717-93585, phiannttarah@yahoo.co.id
}

\begin{abstract}
Every company wants all its equipment or machinery operating in optimum condition, so that the necessary maintenance activities to fulfill that desire. Management of maintenance activities to be hard to do when the equipment or machines owned by increasingly numerous and complex, and activities increase the number of machines or equipment routinely performed. Therefore needed a system to manage maintenance activities quickly, especially in administration of maintenance of machine or equipment are handled. This program has the ability to manage personal data engines, machinery or equipment maintenance scheduling, managing work instruction sheet, a history of the machine, the data parts, data managing maintenance activities, preventive maintenance and expense reports. System maintenance is made by using a computer-based information system maintenance. In making the program used Microsoft Visual Basic 6.0 and used for the purpose of Microsoft Access database.
\end{abstract}

Keywords: maintenance system, preventive maintenance, Microsoft Visual Basic 6.0

\section{Abstrak}

Setiap perusahaan menginginkan semua peralatan atau mesin yang dimilikinya beroperasi dalam keadaan optimum, sehingga diperlukan kegiatan pemeliharaan untuk memenuhi keinginan tersebut. Pengelolaan kegiatan pemeliharaan menjadi sulit dilakukan ketika peralatan atau mesin yang dimiliki semakin banyak dan kompleks serta kegiatan penambahan jumlah mesin atau peralatan semakin rutin dilakukan. Oleh sebab itu diperlukan sebuah sistem pemeliharaan untuk mengelola kegiatan tersebut dengan cepat, terutama dalam kegiatan administrasi pemeliharaan mesin atau peralatan yang ditangani. Program ini memiliki kemampuan untuk mengelola data pribadi mesin, penjadualan pemeliharaan mesin atau peralatan, mengelola lembar instruksi kerja, riwayat mesin, data sukucadang, data pelaksana kegiatan pemeliharaan, dan laporan biaya preventive maintenance. Sistem pemeliharaan dibuat dengan menggunakan sistem informasi perawatan berbasis Komputer. Dalam pembuatan program digunakan Microsoft Visual Basic 6.0 dan untuk keperluan database digunakan Microsoft Access.

Kata Kunci: sistem pemeliharaan, preventive maintenance, Microsoft Visual Basic 6.0

\section{PENDAHULUAN}

Polman Negeri Bangka Belitung terdiri dari dua jurusan yaitu jurusan Teknik Mesin dan Jurusan Teknik Elektonika. Jurusan Teknik Mesin memiliki laboratorium mekanik yang dilengkapi dengan fasilitas mesin-mesin manufaktur sebagai penunjang kegiatan perkuliahan seperti : mesin bubut, mesin bubut CNC, mesin frais, mesin frais CNC, mesin sekrap, mesin bor, mesin gergaji, mesin gerinda datar, mesin gerinda silinder, alat angkat, kompresor, mesin las listrik, EDM, dan mesin-mesin pembentuk logam. Mesin dan peralatan dituntut harus selalu dalam kondisi siap pakai, maka sistem pemeliharaan yang baik mutlak diperlukan, dimana mesin atau peralatan tersebut dapat dipergunakan secara aman oleh mahasiswa dalam melaksanakan praktik perkuliahan dan kegiatan Tridharma Perguruan Tinggi lainnya. Pelaksanaan pemeliharaan yang kurang baik akan menyebabkan kerugian-kerugian yang tidak terhindarkan sehingga investasi yang telah ditanamkan dengan maksud untuk mendapatkan keuntungan dan memberikan manfaat yang besar akan berakibat sebaliknya [1].

Dalam menerapkan fungsi perawatan yang baik selain melaksanakan hal-hal yang bersifat teknis, tak kalah pentingnya juga melakukan kegiatan-kegiatan administratif dengan tertib. Kegiatan ini 
berhubungan dengan pencatatan mengenai segala bentuk kegiatan perawatan yang dilakukan. [2] Datadata perawatan merupakan sesuatu yang sangat penting dalam mengendalikan kegiatan perawatan karena informasi yang ada merupakan dasar penentuan kebijakan perawatan yang akan diambil. Sedemikian pentingnya kegiatan ini sudah selayaknya harus mendapat perhatian yang besar. Pemanfaatan komputer untuk pelaksanaan kegiatan ini akan sangat membantu karena kemudahan yang disediakan akan menghemat waktu yang diperlukan dalam melakukan kegiatan ini bila dibandingkan dengan cara-cara manual [3].

Masalah yang diangkat pada penelitian ini adalah kegiatan pendokumentasian data - data preventive maintenance yang dijalankan pada Laboratorium Mekanik Program Studi Perawatan dan Perbaikan Mesin Polman Negeri Bangka Belitung yang tidak tertib, merupakan akibat dari tidak adanya sistem yang mengatur pelaksanaan kegiatan administratif yang membantu serta mempermudah kegiatan ini. Sehingga data-data perawatan yang penting untuk mengontrol/mengendalikan pelaksanaan preventive maintenance yang dijalankan tidak tersedia, yang meliputi jadual pemeliharaan, data suku cadang, data pelaksana kegiatan, biaya preventive maintenance, lembar instruksi kerja, data pelumas, dan bahkan riwayat mesin tidak tercatat dengan tertib[4].

Berdasarkan uraian diatas, penelitian ini untuk merancang suatu program aplikasi pemeliharaan mesin terjadual yang mampu mengelola dan mendokumentasikan data pribadi mesin, data pelumas tiap jenis mesin/peralatan, penjadwalan preventive maintenance, instruksi kerja, daftar suku cadang, daftar pelaksana perawatan, riwayat mesin, dan data biaya perawatan yang telah dijalankan di Laboratorium Mekanik Polman Negeri Bangka Belitung. Program ini diharapkan dapat memberikan suatu kegiatan administratif preventive maintenance yang lebih baik dan lebih mudah.

Berdasarkan latar belakang yang telah diuraikan di atas yang mengemukakan permasalahanpermasalahan yang ada, maka dapat dirumuskan sebagai berikut.

1. Bagaimana membuat program berkemampuan dalam penjadualan pemeliharaan mesin di Laboratorium Mekanik lebih mudah, baik untuk mesin-mesin lama maupun mesin baru?

2. Bagaimana membuat program aplikasi berkemampuan mengelola dan mendokumentasikan data-data preventive maintenance di Laboratorium Mekanik Polman Negeri Bangka Belitung?

Program aplikasi dikhususkan pada mesin dan peralatan yang ada di Laboratorium Mekanik Polman Negeri Babel yaitu mesin yang mengerjakan baja karbon tinggi dan baja paduan, serta giliran kerja dua shift. Pembuatan database dilakukan dengan memanfaatkan Microsoft Access dan program aplikasinya dijalankan dengan menggunakan Microsoft Visual Basic 6.0.[5]. Data-data yang diambil dan digunakan sebagai contoh dipilih mesin bubut, mesin bor, mesin frais, alat angkat, mesin gerinda datar, mesin gerinda silinder.

Tujuan penelitian ini adalah untuk membuat suatu program dengan kemampuan menjadual pemeliharaan mesin atau peralatan dan membuat database preventive maintenance berupa data pribadi mesin, data pelumasan tiap jenis mesin atau peralatan, Jadual preventive maintenance satu siklus perawatan, Instruksi Kerja bagi teknisi perawatan, data pelaksana kegiatan perawatan, data penggunaan sukucadang, riwayat mesin, dan laporan biaya perawatan mesin.

\section{METODE PENELITIAN}

\subsection{Objek Penelitian}

Mesin dan peralatan yang digunakan sebagai objek dalam penelitian ini dikelompokkan berdasarkan nilai kerumitannya dan karakteristik mesin yaitu: air compressor, Grinding over 30, Grinding up to 30, Metal Cutting up to 30, Metal Cutting up to 150, Handling Equipment Light, Handling Equipment Medium, Heating Furnace over $1000^{\circ} \mathrm{C}$, Heating Furnace up to $1000^{\circ} \mathrm{C}$, Metal Working, dan Miscellaneous [2]. Pemilihan database menggunakan Microsoft Access ini didasari karena Microsoft Access berada dalam lingkup kelompok Microsoft Office yang beroperasi dalam sistem Windows yang sudah tidak asing lagi dijumpai. Dalam pembuatan program aplikasi ini, bahasa pemrograman yang digunakan adalah Microsoft Visual Basic 6.0.[6] dengan alasan fleksibelitasnya yang cukup tinggi, dan mampu berinteraksi dengan aplikasi lain di dalam sistem operasi Windows dari aplikasi yang sederhana sampai aplikasi yang kompleks[7]. 


\subsection{Diagram Alir Penelitian}

Langkah-langkah penelitian ini dibuat dengan tujuan untuk mengarahkan dan memudahkan proses pembuatan dan perancangan sistem, agar hasil yang diinginkan dapat tercapai. Tahapan penelitian secara visual dapat dilihat pada Gambar 1.

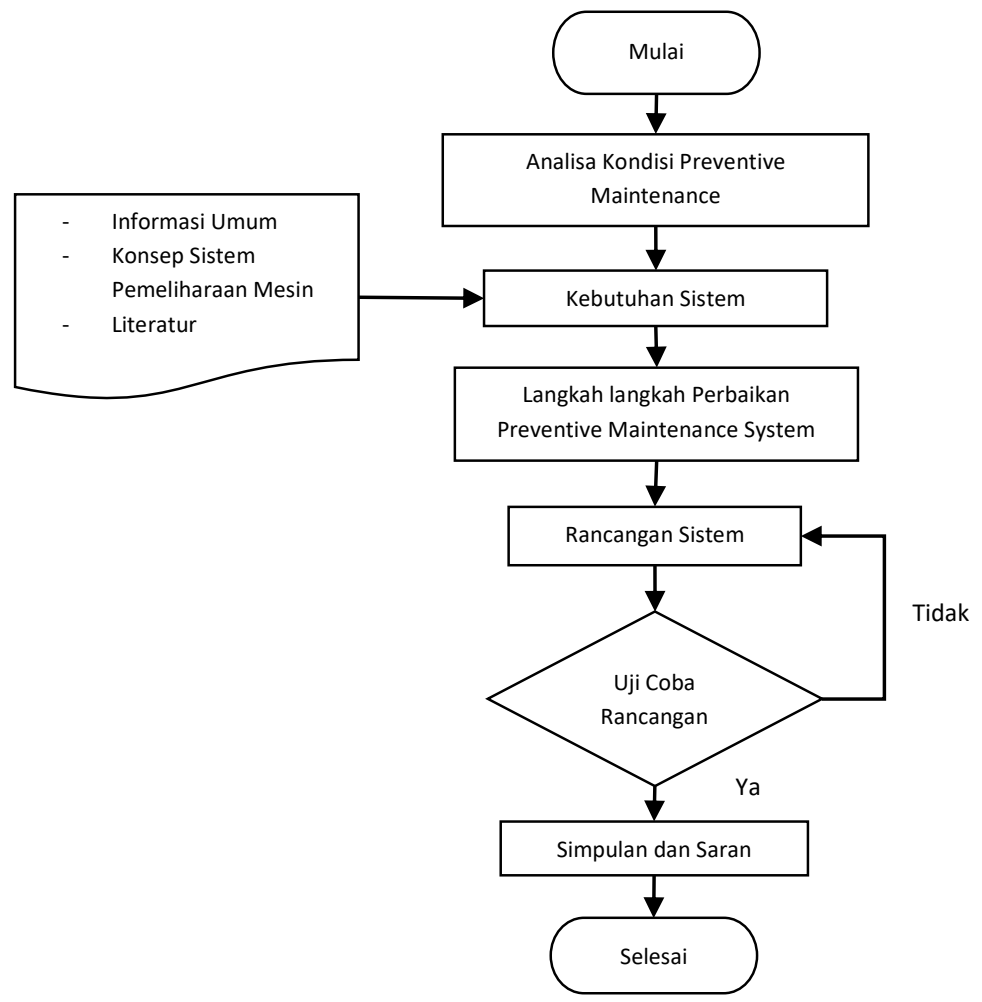

Gambar 1. Diagram Alir Penelitian

\section{HASIL DAN PEMBAHASAN}

\subsection{Analisa Hasil Rancangan}

Pada tahap awal proses perancangan program, dibuat rancangan tampilan secara manual (draft). Draft ini selanjutnya direalisasikan menjadi bentuk-bentuk form tampilan sebenarnya pada pembuatan program. Tampilan-tampilan yang diinginkan sebagai berikut.

$>$ Tampilan login, terdiri dari login, logout, exit

$>$ Tampilan Master data, Data mesin, Data sukucadang, Data SDM, Data spesifikasi kerja, Data pelumasan

Tampilan Jadual Pemeliharaan Mesin, Buat Jadual, Jadual Bulanan, Jadual per mesin

> Tampilan Transaksi Perawatan, Spesifikasi kerja, Riwayat mesin, Input Biaya SDM manual, Input Biaya Sukucadang manual

> Tampilan Laporan, Biaya Perawatan per mesin, Biaya Perawatan Bulanan.

Untuk mempermudah dalam pembuatan tampilan database ini, maka dibuatlah draft tampilan secara manual seperti yang ditunjukkan pada Gambar 2.

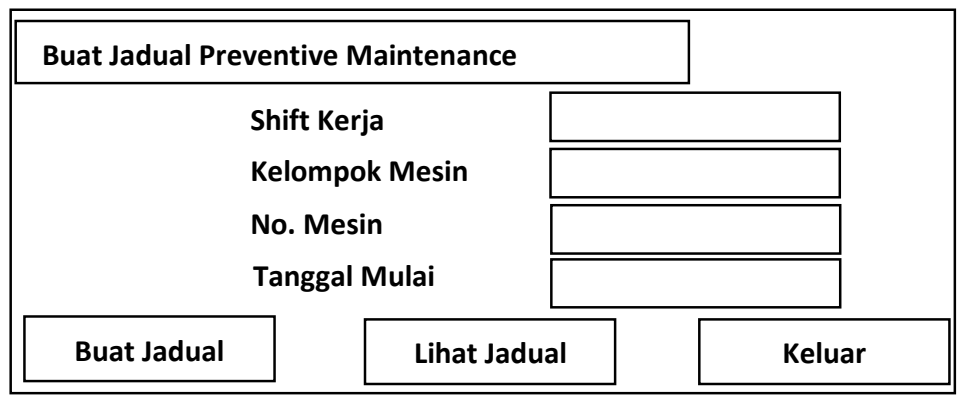

Gambar 2. Contoh Draft Tampilan Penjadualan Pemeliharaan Mesin 


\subsection{Uji coba Program Aplikasi Pemeliharaan Mesin}

Uji coba program merupakan tahapan validasi untuk melihat apakah rancangan program aplikasi bekerja dengan baik. Beberapa contoh uji coba program aplikasi pemeliharaan mesin dengan tampilan sebagai berikut.

\subsubsection{Tampilan Menu Utama}

Menu Utama berisi menu-menu seperti login, master data, jadual pemeliharaan mesin, transaksi perawatan, laporan, dan keluar. User dapat memilih menu sesuai kebutuhan, tampilan menu utama dapat dilihat pada Gambar 3.

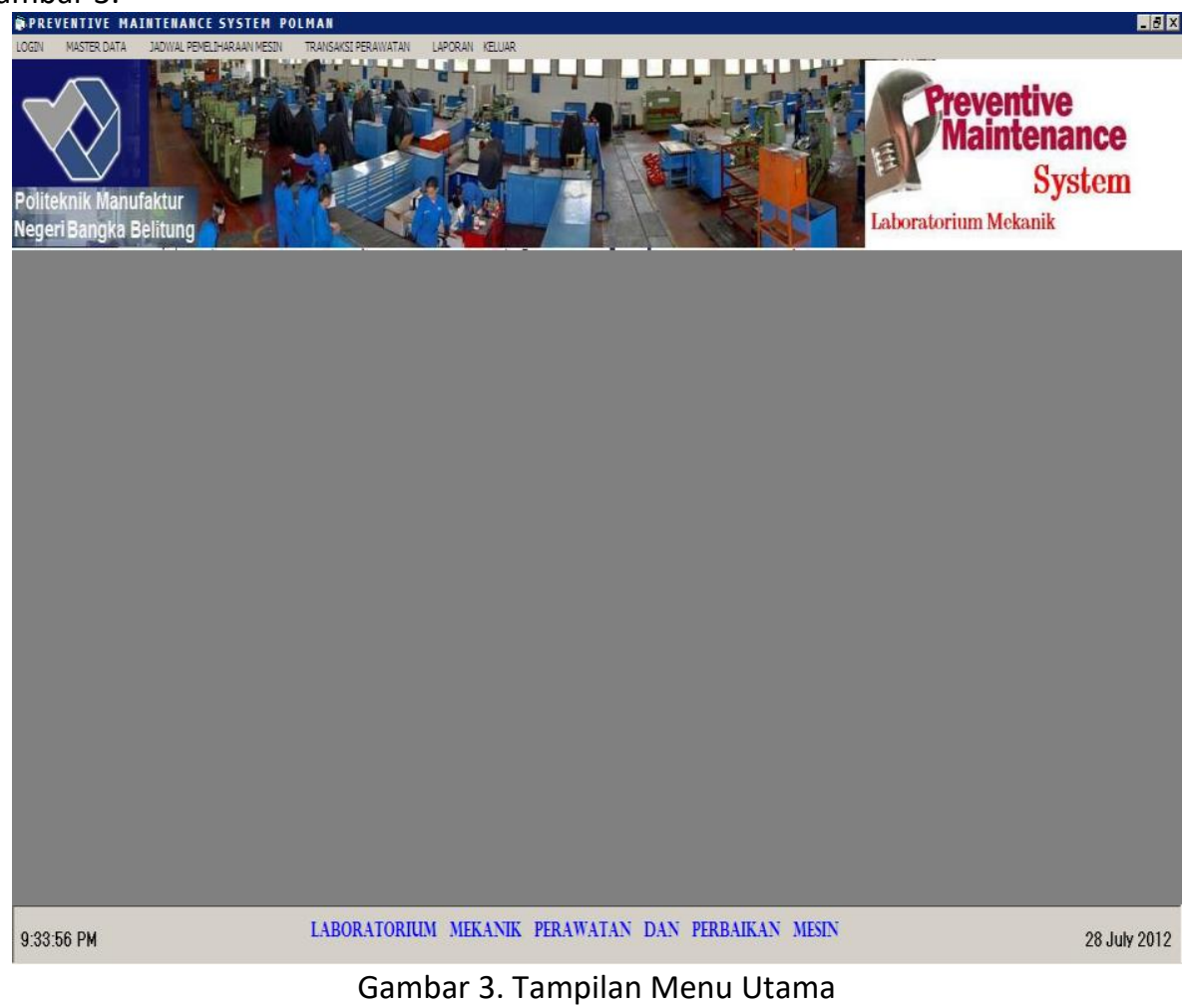

\subsubsection{Tampilan Login}

Tampilan login berisi user name dan password yang bertujuan agar sekuritas data program aplikasi terjaga. User yang terdaftar saja yang dapat mengakses program aplikasi ini. Untuk memulai menjalankan program langkah pertama adalah klik login dan mengisi username dan password yang telah ditentukan kemudian klik OK, selanjutnya user dapat memilih menu yang tersedia sesuai dengan kebutuhannya, tampilan login dapat dilihat pada Gambar 3.

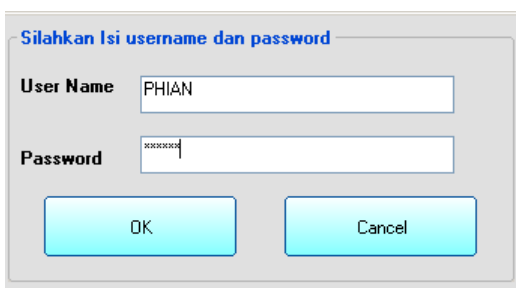

Gambar 4. Tampilan Login

\subsubsection{Tampilan Buat Jadual Pemeliharaan Mesin}

Form ini berfungsi membuat jadual pemeliharaan mesin satu siklus penuh, user dapat menentukan mesin yang akan dibuat jadual pemeliharaan berdasarkan shift kerja dan kelompok mesin yang sesuai. Jadual kemudian bisa dilihat dengan cara klik lihat jadual. Tampilan form buat Jadual Pemeliharaan Mesin dapat dilihat pada Gambar 5. 


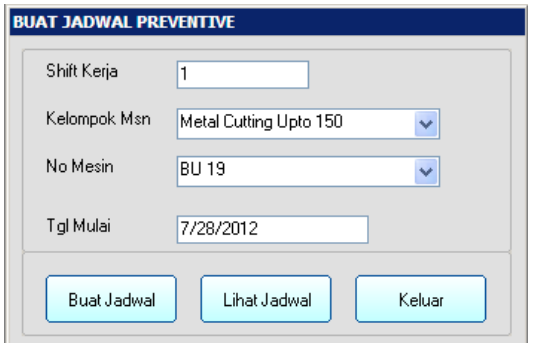

Gambar 5. Tampilan Form Buat Jadual Pemeliharan Mesin

\subsubsection{Tampilan Form Jadual kegiatan Pemeliharaan Mesin}

Form ini berkemampuan menampilkan dan mencetak jadual pemeliharaan mesin berdasarkan interval waktu yang dipilih sesuai kebutuhan user. Mesin-mesin yang telah dibuat jadual dapat dilihat pada form ini berdasarkan waktu yang telah dipilih. Form ini juga bisa melihat jadual pemeliharaan mesin untuk satu jenis mesin yang dipilih berdasarkan waktu yang ditentukan oleh user secara visual dapat dilihat pada Gambar 6.

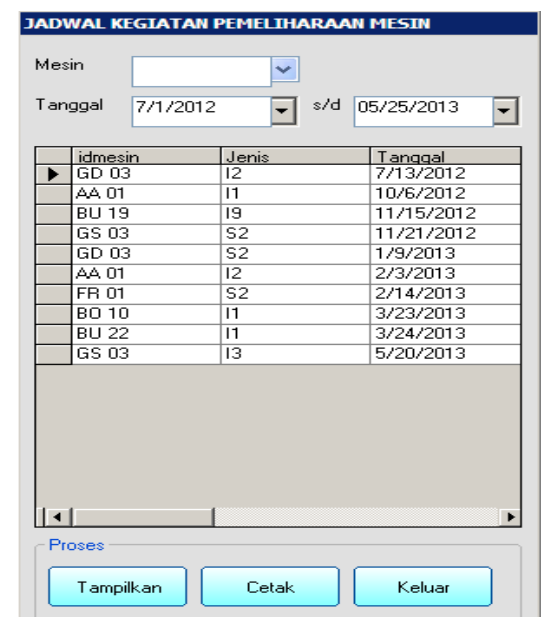

Gambar 7. Tampilan Laporan Kerusakan

\subsubsection{Tampilan Form Data SDM Pelaksana Pemeliharaan Mesin}

Data SDM merupakan master data yang berisi data pelaksana kegiatan pemeliharaan mesin, data dapat diedit, disimpan, dihapus, atau ditambah sesuai dengan kebutuhan user. Tampilan form data SDM pelaksana pemeliharaan mesin dapat dilihat pada Gambar 8.

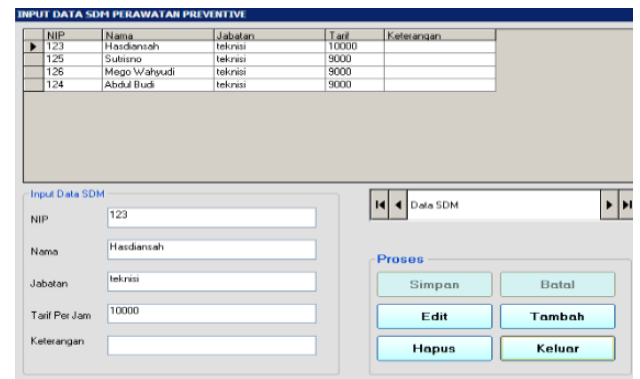

Gambar 8. Tampilan Form Data SDM Pelaksana Pemeliharaan Mesin

\subsubsection{Tampilan Form Spesifikasi Kerja Pemeliharaan Mesin}

Form spesifikasi kerja berisi data-data spesifikasi kerja tiap mesin, dengan kemampuan simpan, edit, hapus, dan tambah atau batal. User dapat mengubah, mengedit,menghapus data spesifikasi sesuai dengan kebutuhan. Tampilan form spesifikasi dapat dilihat pada Gambar 9. 


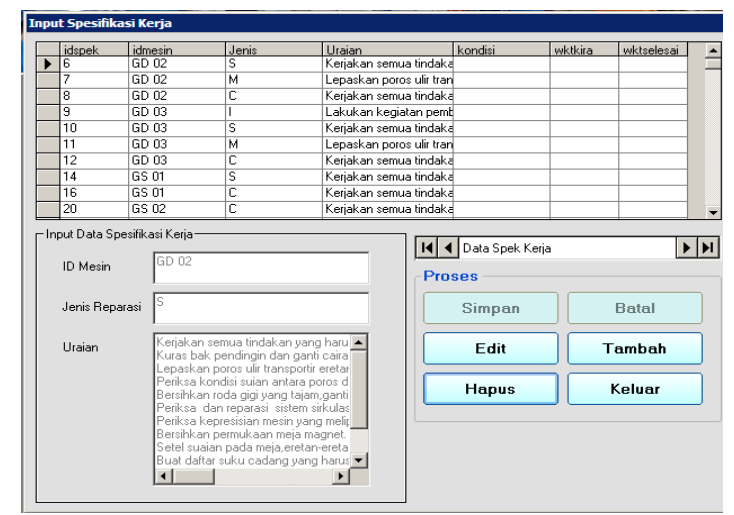

Gambar 9. Tampilan Form Spesifikasi Kerja pemeliharaan Mesin

\subsubsection{Tampilan Data Pelumasan Mesin}

Data pelumasan tiap model mesin dapat dikelola pada form ini, user dapat melakukan tindakan sesuai kebutuhan seperti perintah edit, tambah, batal, hapus, dan simpan, serta dapat dicetak. Tampilan form Data Pelumasan Mesin dapat dilihat pada Gambar 10.

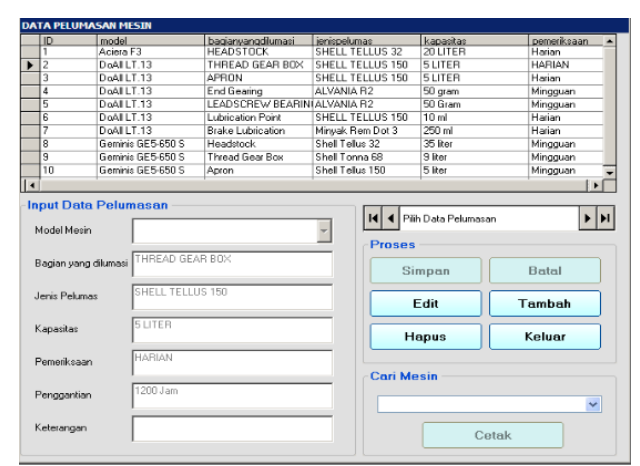

Gambar 10. Tampilan Form Data Pelumasan Mesin

\subsubsection{Tampilan Form Jadual Bulanan Preventive Maintenance}

Form ini berisi jadual bulanan pemeliharaan mesin. User bisa memilih bulan dan tahun sesuai kebutuhan, form ini juga dapat mencetak lembar spesifikasi kerja. Tampilan form jadual bulanan preventive maintenance dapat dilihat pada Gambar 11.

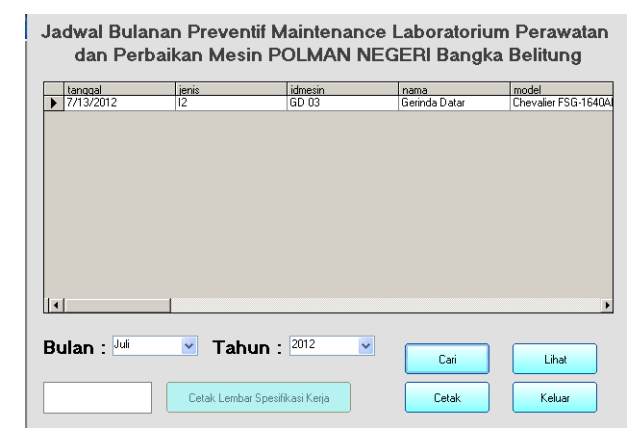

Gambar 11. Tampilan Form Jadual Bulanan Preventive Maintenance

\subsubsection{Tampilan Form Pemakaian SDM}

Form ini merupakan form isian manual pemakaian tenaga kerja pelaksana kegiatan perawatan mesin. Form ini dapat dijadikan sebagai laporan penggunaan SDM dalam tiap kegiatan pemeliharaan yang telah dilaksanakan. Tampilan form pemakaian SDM dapat dilihat pada Gambar 12. 


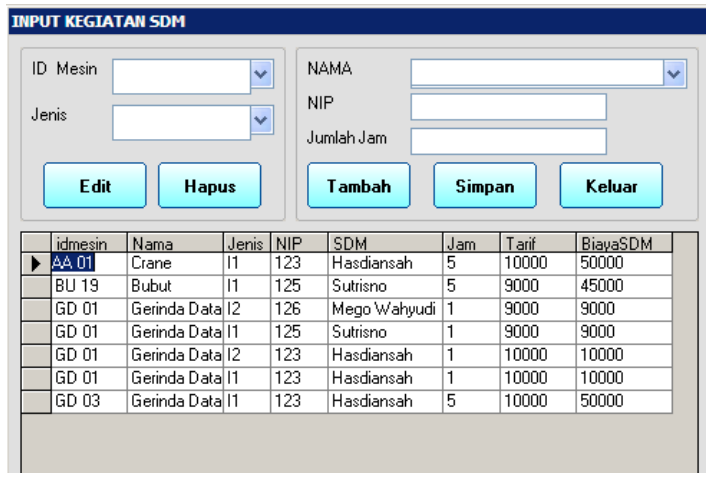

Gambar 12. Tampilan Form Pemakaian SDM (Tenaga Kerja)

\subsubsection{Tampilan Form}

Form ini berisi data sukucadang yang digunakan pada kegiatan perawatan. Form diinput manual dengan dukungan master data SDM dan master data sukucadang. Tampilan form pemakaian sukucadang dapat dilihat pada Gambar 13.

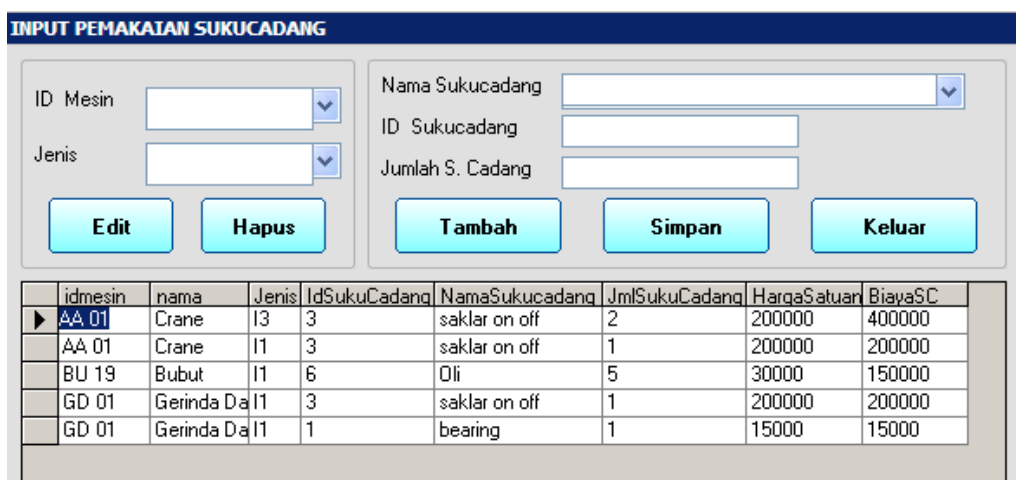

Gambar 13. Tampilan Form Pemakaian Sukucadang

\subsubsection{Tampilan Form Laporan Preventive Maintenance}

Form ini menampilkan laporan biaya bulanan kegiatan pemeliharaan mesin. User dapat menentukan bulan dan tahun sesuai kebutuhan, data-data yang dipilih dapat dicetak. Tampilan form laporan preventive maintenance dapat dilihat pada Gambar 14.

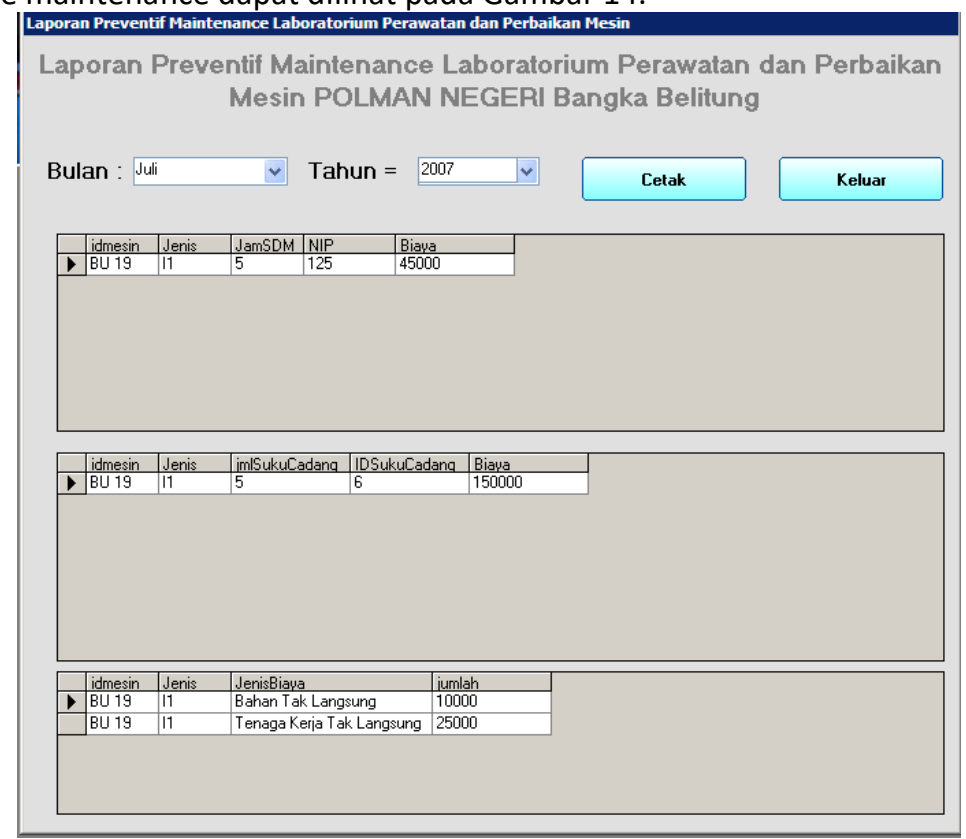

Gambar 14. Tampilan Form Laporan Preventive Maintenance 


\section{SIMPULAN}

Dari pembahasan yang dilakukan pada tahapan analisa dan uji coba dapat ditarik kesimpulan yaitu program aplikasi yang dibuat dapat dijalankan sesuai dengan rancangan, hal ini dibuktikan dengan tampilan program yang muncul sesuai dengan perintah yang diberikan oleh pengguna (user), secara detail dapat ditarik suatu kesimpulan sebagai berikut:

1. Program aplikasi dengan kemampuan menjadual pemeliharaan mesin satu siklus mulai dari commissioning hingga complete overhoul tersedia, jadual pemeliharaan bulanan, tahunan, dan jadual pemeliharaan tiap mesin mampu ditampilkan.

2. Data-data maintenance terdiri dari data pribadi mesin, data pelumas, riwayat mesin, data sukucadang, data pelaksana kegiatan perawatan, data biaya perawatan, dan spesifikasi keja tersimpan dalam suatu database dan program aplikasi mampu mengelola data-data tersebut.

\section{DAFTAR PUSTAKA}

[1] Mobley R. Keith, Maintenance Fundamentals, USA: Elsevier Buterworth- Heinemann, 2004.

[2] Garg. H. P, Industrial Maintenance, New Delhi: S. Chand \& Company LTD, 1976.

[3] Mobley, R. Keith, Maintenance Engineering Handbook, New York: McGraw-Hill Companies, 2008.

[4] Corder, Antony, Teknik Manajemen Pemeliharaan, alih bahasa : Kusnul Hadi, Jakarta: Erlangga, 1992.

[5] Supardi, Yuniar, Semua Bisa Menjadi Programmer VB 6 Hingga VB 2008 Basic, Jakarta: PT Elek Media Komputindo, 2011.

[6] Kristanto, Harianto, Konsep dan Perancangan Database, Yogyakarta: Andi, 1994.

[7] Sadeli, Muhammad, Aplikasi Database dengan Visual Basic 6 untuk Orang Awam, Palembang: Maxicom, 2008. 